\title{
Representação política discursiva e
} movimento social dos surdos: coletivização de questões como fonte de autoridade ${ }^{1}$

Discursive political representation and social movement of the deaf: turning issues collective as a source of authority

Representación política discursiva y movimiento social de los sordos: colectivización de cuestiones como fuente de autoridad

Regiane Lucas de Oliveira Garcêz

- Pós-doutora e doutora em Comunicação Social pela Universidade Federal de Minas Gerais (UFMG)

- Mestre em Comunicação Social e graduada em Jornalismo pela UFMG

- Professora adjunta do Departamento de Comunicação Social da UFMG

- E-mail: regianelucasgarcez@gmail.com 


\section{3}

\section{ANO $14 \cdot$ NÚMERO 26 • 1은. $2017 \cdot$ ORGANICOM \\ REPRESENTAÇÃO POLÍTICA DISCURSIVA E \\ MOVIMENTO SOCIAL DOS SURDOS: COLETIVIZAÇÃO \\ DE QUESTÕES COMO FONTE DE AUTORIDADE}

\section{Resumo}

Discute-se a noção de representação política discursiva (Saward, 2010) e 0 uso de fontes de autoridade por lideranças do movimento social dos surdos para buscar legitimidade nos discursos sobre modelos educacionais. Realizou-se um mapeamento de claims em um grupo de lideranças no Facebook, em uma audiência pública e na Conferência Nacional dos Direitos da Pessoa com Deficiência. Conclui-se que a principal fonte de autoridade está relacionada à coletivização de questões, seja na defesa do amplo interesse ou nas histórias narradas comuns aos surdos.

\section{PALAVRAS CHAVE: MOVIMENTOS SOCIAIS •REPRESENTAÇÃO POLITICA DISCURSIVA • EDUCAÇÃO DE SURDOS • FONTES DE AUTORIDADE.}

\section{Abstract}

The notion of discursive political representation is discussed (Saward, 2010) as well as the use of sources of authority by leaders of the social movement of the Deaf to pursue legitimacy in the speeches regarding educational models. A mapping of claims was drawn with a group of leaders on Facebook, in a public hearing session and in the Brazilian National Conference on the Rights of Persons with Disabilities. A conclusion reached is that the main source of authority derives from turning the issues collective, either for the defense of the broad interest or in the narrated histories, shared by the deaf individuals.

\section{KEYWORDS: SOCIAL MOVEMENTS • DISCURSIVE POLITICAL REPRESENTATION • DEAF PEOPLE EDUCATION • SOURCES OF AUTHORITY.}

\section{Resumen}

Se argumenta la noción de representación política discursiva (Saward, 2010) y el uso de fuentes de autoridad por los líderes del movimiento social de los sordos a buscar legitimidad en discursos sobre modelos educativos. Se realizó un mapeo de las reclamaciones en un grupo de líderes en Facebook, una audiencia pública y la Conferencia Nacional de los Derechos de las Personas con Discapacidad. Se concluye que la principal fuente de autoridad es la colectivización de las cuestiones, es la idea de amplio interés o historias comunes a los sordos. 


\section{ANO 14 • NÚMERO 26 • 1ํSEM. 2017 - ORGANICOM REPRESENTAÇÃO POLÍTICA DISCURSIVA E MOVIMENTO SOCIAL DOS SURDOS: COLETIVIZAÇÃO DE QUESTÕES COMO FONTE DE AUTORIDADE}

U

ma grande questão que se coloca contemporaneamente à comunicação pública das organizações sociais é quem fala em nome de quem. Quem são os agentes de advocacy? Quem são os representantes das organizações? Eles falam em nome de quem: das organizações ou dos públicos por elas representados? As organizações são, elas mesmas, representantes? Essa representação é legítima? E no caso de movimentos sociais ou organizações conformadas por sujeitos em situação de extrema vulnerabilidade, como identificar e atribuir legitimidade?

Essas são questões cada vez mais recorrentes na cena pública e que não possuem uma pronta resposta. Não pretendemos responder tais indagações neste artigo, mas, com base nelas, lançar luz sobre os processos de representação política que acontecem nas organizações e que resultam nos atos de falar e agir em nome de alguém ou de alguma organização. Buscamos compreender essas dinâmicas a partir da noção de representação discursiva, também chamada de representação não eleitoral, cuja comunicação se revela central principalmente na obra de Michael Saward (2009, 2010). Desse modo, a questão central deste estudo é, analisando a atuação do movimento social das pessoas surdas, investigar como esse movimento e organizações que o compõem são representados, como suas demandas são traduzidas para um vocabulário público e quais as fontes de autoridade as lideranças utilizam para buscar legitimidade.

Acredita-se que a noção de representação discursiva ou não eleitoral (Garcêz, 2013; Garcêz e Maia, 2017; Saward, 2010; Dryzek e Niemayer, 2008) pode trazer contribuições aos estudos da comunicação organizacional, especialmente no caso de organizações da sociedade civil e movimentos sociais. Destacamos aqui quatro contribuições. Em primeiro lugar, uma noção alargada dos processos de representação ajuda a explicar por que surgem lideranças que não necessariamente obedecem à regra dos escolhidos. Nem sempre os líderes são os presidentes das associações comunitárias ou os escolhidos em assembleias. 0 mesmo acontece com a escolha dos porta-vozes ao falar com a imprensa. Em segundo lugar, 0 artigo auxilia na compreensão dos processos de configuração da legitimidade dos porta-vozes. Ela varia de acordo com a demanda representada e com a audiência ou o público para quem se fala, num amplo movimento, difuso e multidirecional. Em terceiro, lança luz sobre as ambiguidades internas próprias dos movimentos sociais, dos processos de configuração de um nós (Melucci, 1996) e de delegação de poder e de responsabilidades. Por fim, a existência de grupos de advocacy locais ou transnacionais aciona um processo de representação que vai além da localidade e que pode ser mais bem compreendido por meio de uma abordagem processual e discursiva. São organizações como Unesco ou Greenpeace, assim como os agentes autoautorizados, artistas que dizem representar um grupo de pessoas ou organizações da sociedade civil como coletivos juvenis, associações de bairro ou do terceiro setor.

No caso do movimento social das pessoas surdas, a questão da representação se revela central visto que historicamente pais, professores e autoridades negaram seu protagonismo em nome da tutela creditada à falsa ideia de incapacidade (Lanna Júnior, 2010). As associações de surdos permaneceram no anonimato por anos devido à proibição do uso da língua de sinais (Lane; Pillard; Hedberg, 2011); o movimento social sofre constantemente a deslegitimação por parte de autoridades (Campello; Rezende, 2014); e a representação nos espaços institucionais é frequentemente questionada.

No caso analisado, o movimento surdo passou por uma retomada em 2011, motivada pela ameaça de fechamento de uma escola federal centenária, o Instituto Nacional de Educação dos Surdos (INES), localizado no Rio de Janeiro (FariaNascimento; Costa, 2014). 0 fechamento foi determinado por conta da Política Nacional de Educação Especial na Perspectiva da Educação Inclusiva (2008), do Ministério da Educação, que proibia matrículas em escolas exclusivamente de surdos ou de outras deficiências. Assim, haveria o progressivo fechamento dessas instituições e os alunos seriam encaminhados para escolas comuns. A principal luta do movimento era a defesa da escola bilíngue, onde a língua de instrução seria a Língua 


\section{ANO 14 • NÚMERO 26 • 1ํㅡㄴ. 2017 - ORGANICOM \\ REPRESENTAÇÃO POLÍTICA DISCURSIVA E \\ MOVIMENTO SOCIAL DOS SURDOS: COLETIVIZAÇÃO \\ DE QUESTÕES COMO FONTE DE AUTORIDADE}

Brasileira de Sinais (Libras) e onde o português seria ensinado como segunda língua. 0 movimento surdo atuou em várias frentes, como legislativo, executivo, judiciário e esferas de participação. Desenvolveram-se estratégias de comunicação, mobilização e lobbies diversos. Para este artigo, escolhemos analisar a representação do movimento nos âmbitos do judiciário, da conferência de direitos e de um grupo de lideranças no Facebook.

Na primeira seção discutimos as contribuições da noção de representação política não eleitoral para a compreensão da comunicação nos movimentos sociais. Em seguida, apresentamos a noção de fontes de autoridade, o corpus, a metodologia de mapeamento dos claims e a análise baseada nas fontes de autoridade acionadas. Na terceira seção apresentaremos os resultados. Concluiremos que a principal fonte de autoridade acionada diz respeito à coletivização das questões, seja por meio da ideia de amplo interesse ou por meio das histórias comuns aos surdos.

\section{REPRESENTAÇÃO NÃO ELEITORAL E MOVIMENTOS SOCIAIS}

Os estudos sobre representação não eleitoral (Urbinatti, 2006; Urbinati e Warren, 2008), também chamada de representação discursiva (Dryzek; Niemayer, 2008), emergem do campo da ciência política a partir do questionamento da teoria clássica sobre representação política. Os autores discutem que o entendimento da representação conforme os critérios numéricos do voto e de territorialidade já não dão conta de explicar fenômenos contemporâneos como as inovações institucionais participativas e a crise da representação eleitoral.

Autores contemporâneos têm conferido centralidade aos processos de representação em vez de focar apenas em resultados ou eleições. Iris Young (2000) aponta para uma representação de perspectivas ou pontos de vista, ao invés de representação por território ou por eleitores. Dryzek e Niemeyer (2008) destacam a discursividade dos processos de falar e/ou agir em nome de. Leonardo Avritzer (2008) denomina de representação por afinidade as articulações que ONGs e sujeitos estabelecem entre si. Saward $(2009 ; 2010)$ nomeia as demandas de representação (representative claim) como "um contínuo processo de fazer e receber, de aceitar e rejeitar demandas - entre e fora dos períodos eleitorais" (Saward, 2010, p. 36). 0 que há de comum nessas abordagens é o fato de a representação se dar fora dos momentos eleitorais; de englobar a política formal e informal; de referir-se não apenas a pessoas, mas a perspectivas, valores ou discursos; e de frisar a ausência de procedimentos formais de eleição e de prestação de contas.

A representação como atividade(Pitkin, 1967)² é um processo difuso, criativo, incompleto e aberto a revisões. A comunicação é, assim, dimensão constitutiva da representação (Mansbridge, 2003). Ao compreender a atividade de falar em nome de, lançamos um olhar capaz de revelar a complexidade da representação, considerando as múltiplas dimensões compostas por fatores sociais, culturais e aspectos não apenas substantivos, mas também simbólicos (Saward, 2010).

Entretanto, o fato de ser aberta, difusa e incompleta não faz da representação um "vale tudo", onde todos podem falar em nome de todos. "A representação deve ser altamente produtiva, perseguida como estável e legítima, e deve alimentar a política democrática, sem ser de alguma forma ideal ou completa em alguma instância" (Saward, 2010, p. 23). É natural da atividade de representar que proferimentos acionem fontes de autoridade para se mostrarem legítimos (Saward, 2009). E a legitimidade, em contrapartida, advém do processo discursivo e dialógico que se dá entre audiência, representante, objeto representado. Em suma, a legitimidade é uma conjugação de elementos extraídos de quem, o quêe como se representa (Saward, 2010).

2 Hannah Pitkin (1967) é considerada a precursora dessa guinada discursiva dos estudos de representação (Disch, 2011) ao questionar a representação baseada no modelo eleitoral. 


\section{ANO 14 • NÚMERO 26 • 1ํSEM. 2017 • ORGANICOM REPRESENTAÇÃO POLÍTICA DISCURSIVA E MOVIMENTO SOCIAL DOS SURDOS: COLETIVIZAÇÃO DE QUESTÕES COMO FONTE DE AUTORIDADE}

Sob uma perspectiva discursiva da representação e das lutas sociais, argumentamos que os movimentos sociais, ainda que não eleitos formalmente, se organizam a partir de uma dinâmica representativa. Essa abordagem supera as dimensões dos movimentos sociais exclusivamente conflitiva (Tilly, 2003; Tarrow, 1998) ou estratégica (McCarthy; Zald, 2009). Busca-se aproximar das correntes interacionistas, cujas preocupações estão voltadas para os componentes cognitivos, simbólicos e ideológicos dos fenômenos coletivos. Essa perspectiva vê "os movimentos sociais como agentes de significação engajados na produção e manutenção de sentidos que envolvem protagonistas, antagonistas e expectadores" (Snow, 2004, p. 384). Engajados em uma política de significação, tais atores lutariam por redefinições simbólicas e pelo estabelecimento e circulação de novos enquadramentos da ação coletiva.

Compreender os movimentos sociais a partir da representação discursiva é uma forma de dialogar com esse conjunto de estudos que confere destaque às interações sociais e à produção simbólica. Os pontos de vista internos a um grupo podem ser distintos, mas, para que sujeitos exerçam pertença e conformem uma coletividade, devem partilhar sentidos que promovam uma identificação mútua. A representação política discursiva é um meio de conduzir aos processos de pertença e identificação, de forma muitas vezes conflitiva e estratégica, mas sempre interacional e dialógica, como meio de organizar internamente esse grupo, mesmo que provisoriamente.

Assim, a representação exercida pelos movimentos sociais, ao mesmo tempo em que organiza e delimita o grupo, constrói um discurso para fora dele no sentido de pluralizar a representação nas diversas instâncias. Os movimentos sociais e as associações cívicas têm desempenhado importante papel nessa pluralização da representação (Weldon, 2011; Maia, 2012; Warren, 2001). Na maioria das vezes, por estarem mais próximos do cotidiano dos sujeitos, são capazes de identificar situações de opressão e de torná-las públicas por meio de um vocabulário comum. Demandas que emergem de elementos biográficos e individuais são reelaboradas de modo a organizar o discurso de um grupo inteiro e lidar com a heterogeneidade interna a ele (Melucci, 1996; Garcêz e Maia, 2009). 0 potencial democrático das associações e dos movimentos sociais, não dado a priori, se constitui na abertura à pluralidade dos pontos de vista internos e à capacidade de inserir novos temas na arena pública.

\section{FONTES DE AUTORIDADE, MAPEAMENTO DE CLAIMSE ANÁLISE SISTÊMICA}

Conforme mencionou Saward $(2009,2010)$, as demandas de representação podem ou não ser aceitas ou aceitáveis tanto pelas audiências ou pelos destinatários da representação quanto pelo grupo de representados. Movimentos sociais apresentam suas demandas de representação, mas quais critérios utilizar para aceitar essas demandas? Quais são mais ou menos legítimas? Nesse sentido, Saward (2009) elencou um conjunto de fontes de autoridade que são a base da justificação de uma demanda de representação, ou seja, o porquê da sua possível legitimidade. Para os propósitos da nossa pesquisa dividimos nossa análise em duas etapas. Primeiro identificamos queme o que se representa, nomeando lideranças, gestores do Ministério da Educação (MEC), representantes políticos, bem como os cargos ocupados e os seus posicionamentos: se defendem a escola bilíngue, a escola regular inclusiva ou ambas. Em seguida, na tentativa de mostrar o comose representa, mapeamos as fontes de autoridade acionadas, numa adaptação da proposta de Saward (2009), conforme segue: a) história pessoal (experiências vivenciadas ou presenciadas); b) história do povo surdo (experiências comuns a surdos de todo 0 mundo, como exclusão, proibição do uso das línguas de sinais, criação de instituições escolares históricas, marcos e eventos importantes); c) identidade adscritiva ${ }^{3}$ (características comuns a pessoas de um grupo, expressa nos corpos ou no modo

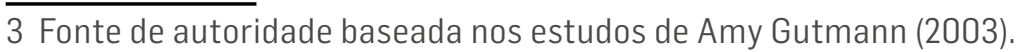




\section{ANO 14 • NÚMERO 26 • 1ํSEM. 2017 - ORGANICOM \\ REPRESENTAÇÃO POLÍTICA DISCURSIVA E \\ MOVIMENTO SOCIAL DOS SURDOS: COLETIVIZAÇÃO \\ DE QUESTÕES COMO FONTE DE AUTORIDADE}

de comunicar); d) autoadscrição (reforço da identidade adscritiva); e) credencial (menção ao próprio cargo); f) "expertise" científica (conhecimentos científicos sobre o tema); g) expertise profissional (experiência e conhecimentos práticos, adquiridos por meio da profissão); h) expertise legal (conhecimentos da legislação e de políticas públicas); i) amplo interesse (interesse da maioria); j) ações desenvolvidas (ações políticas e resultados dessas ações).

Analisamos os proferimentos conforme essas fontes de autoridade. As unidades de análise são o que Saward (2010, p. 42) chama de claim: "uma demanda de representar, ou uma demanda de quem sabe que representa 0 interesse de alguém ou de alguma coisa". Coletamos 128 demandas de representação em três arenas de atuação do movimento, sendo 47 delas expressas por surdos e 26, por pessoas com outra deficiência4:

- Audiência pública da Procuradoria Federal dos Direitos do Cidadão: realizada no dia 01 de dezembro de 2011, na Procuradoria-Geral da República, em Brasília, com o tema "Educação inclusiva: plano nacional de educação e escolas especiais". Contou com cerca de cem pessoas, entre promotores e procuradores de várias estados e ativistas do movimento surdo e do movimento inclusivista. Teve como objetivo a obtenção de conhecimentos multidisciplinares e dados sobre a educação das pessoas com deficiência para aprimorar a atuação do Ministério Público Federal. Foi desencadeada por uma carta-denúncia do movimento surdo sobre o desrespeito linguístico promovido pelas políticas de inclusão do governo. Foram extraídos 36 proferimentos, a maior parte de vinte a trinta minutos.

- Conferência Nacional dos Direitos da Pessoa com Deficiência: realizada entre os dias 3 e 6 de dezembro de 2012, em Brasília, teve o objetivo de produzir propostas que pudessem embasar as políticas públicas para pessoas com deficiência nos níveis municipal, estadual e nacional ${ }^{5}$. 0 evento foi organizado pelo Conselho Nacional dos Direitos da Pessoa com Deficiência (Conade) ${ }^{6}$. Participaram cerca de 2 mil pessoas, entre as quais 886 eram delegados, 49 deles surdos. 0 corpus consistiu nos proferimentos expressos na abertura, no GT de Educação, na plenária final e no encerramento, em temas que tratavam exclusivamente da educação de surdos. Foram extraídos 62 proferimentos com tempo de um a seis minutos.

- Facebook: o grupo foi criado em abril de 2011, com o objetivo de organizar a manifestação que ocorreu em Brasília em maio daquele ano. É composto pelas lideranças do movimento surdo e conta com 184 membros ${ }^{7}$. Depois da manifestação continuou funcionando como fórum de articulação em ações de mobilização. Analisamos 28 vídeos, exclusivamente em língua de sinais (libras), publicados em 2011, com tempo de um a quatro minutos.

Após a identificação dos claims nas arenas, realizamos a codificação no software NVivo, com finalidade exclusiva de comparação entre arenas e entre códigos. Analisamos a representação política discursiva numa perspectiva processual e móvel, a partir de uma abordagem sistêmica, que leva em conta o fluxo das demandas de representação em diferentes arenas $^{8}$. A característica difusa dos discursos não nos permite analisar os direcionamentos dos claims, mas padrões, recorrências e desconexões entre arenas.

\footnotetext{
4 A audiência durou sete horas e gerou uma transcrição de 124 páginas. A conferência usou a tecnologia da estenotipia (legendas em tempo real, projetadas em um telão), que gerou arquivos digitais de texto, cedido pelo Conselho Nacional dos Direitos da Pessoa com Deficiência (Conade). A seleção do corpus foi realizada a partir da leitura das transcrições num total de 631 páginas. Já no Facebook foram encontradas 2.052 postagens em 2011, desconsiderando comentários, sendo elas em língua de sinais (libras) e/ou em língua portuguesa. Mantivemos apenas os vídeos, chegando a 589 postagens. Em seguida excluímos postagens sobre questões operacionais de mobilização e as não ligadas à temática do movimento. Elegemos cinco lideranças nacionais principais e quatro estaduais e selecionamos as suas postagens com engajamento (curtidas e comentários) acima de 50, chegando a 28 postagens. Pusemos o foco nos conteúdos que expressavam o posicionamento político do movimento. Optou-se por assistir os vídeos na própria língua de sinais, sem transcrição.

5 As propostas aprovadas foram incluídas em um documento encaminhado para vários ministérios, na perspectiva de estabelecerem políticas transversais relacionadas à pessoa com deficiência.

6 Órgão da Secretaria Nacional de Promoção dos Direitos da Pessoa com Deficiência (SNPD), vinculada à Secretaria de Direitos Humanos da Presidência da República.

7 Acesso em 21/09/2014.

8 A abordagem sistêmica foi inspirada nos autores deliberacionistas que, numa terceira fase, optaram por considerar diversos momentos, arenas e temporalidades da deliberação (Mansbridge et al., 2012).
} 


\section{ANO 14 • NÚMERO 26 • 1ํSEM. 2017 • ORGANICOM \\ REPRESENTAÇ̃̃O POLÍTICA DISCURSIVA E MOVIMENTO SOCIAL DOS SURDOS: COLETIVIZAÇÃO \\ DE QUESTÕES COMO FONTE DE AUTORIDADE}

\section{A LEGITIMIDADE DA REPRESENTAÇÃO: FONTES DE AUTORIDADE E COLETIVIZAÇÃO DE DEMANDAS}

Nos 128 claims foram acionadas, ao todo, 383 fontes de autoridade, uma média de três por proferimento. As fontes de autoridade foram distribuídas conforme o Gráfico 1, abaixo:

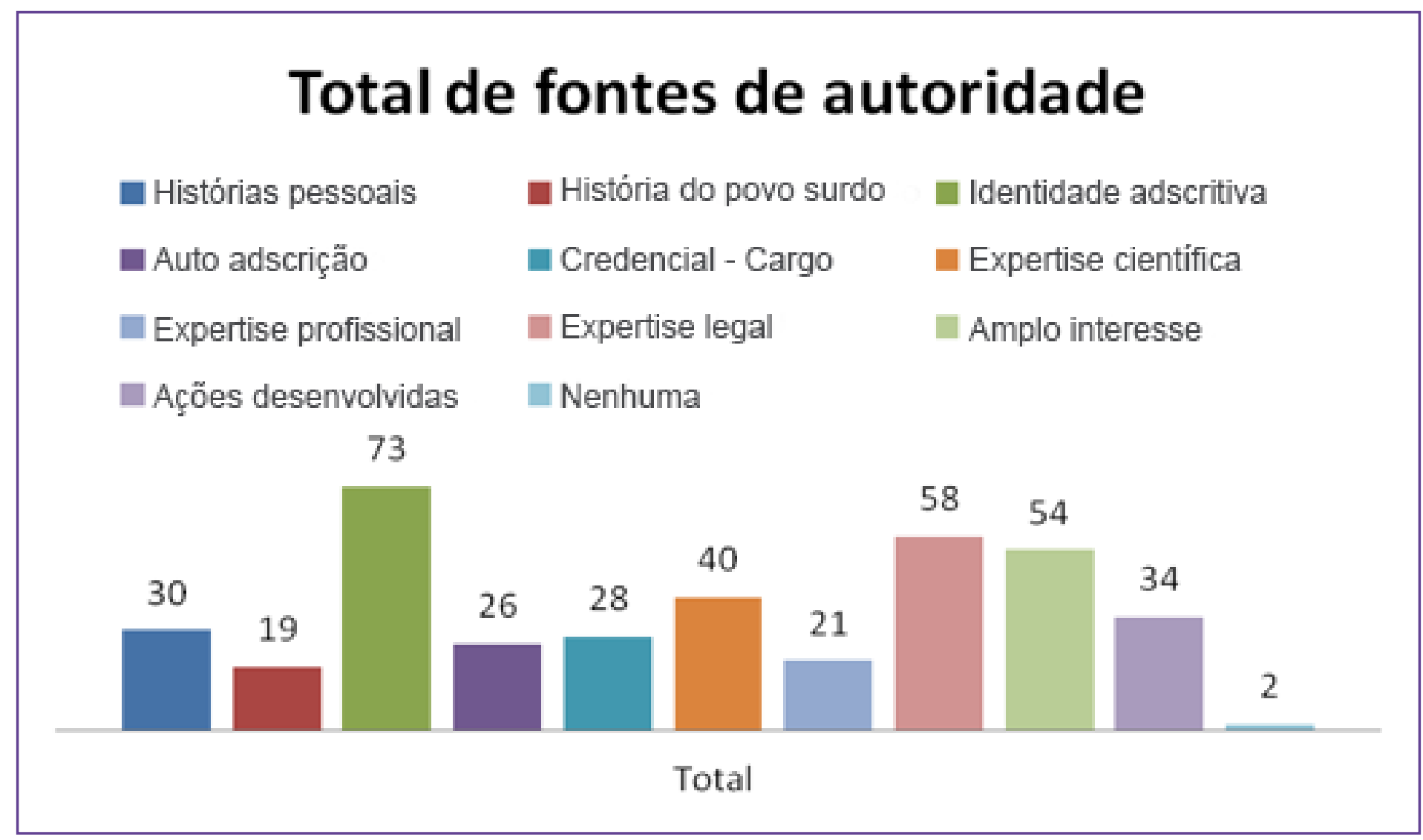

Gráfico 1: Total de fontes de autoridade.

Há que se destacar que 73 dessas fontes dizem respeito à condição física da pessoa surda ou com deficiência. Nem sempre as fontes de autoridade são acionadas por mecanismos verbais, mas fisicamente, pela própria presença, o que denominamos de identidade adscritiva (representada pela barra verde). No geral, os conhecimentos legais sobre a educação de surdos foram bastante acionados, num total de 58 fontes. Em seguida, claims baseados no amplo interesse foram convocados 54 vezes, seguidos dos conhecimentos científicos, 40 vezes. Na sequência, 34 ações desenvolvidas mencionadas, 30 histórias pessoais, 28 credenciais, 26 autoadscrições, 21 experiências profissionais e 19 histórias do povo surdo.

Para além de uma quantificação da frequência e dos tipos de fonte de autoridade acionadas, interessa-nos compreender, a partir de uma perspectiva discursiva, como elas mudam de arena para arena. Evidenciam-se tanto ações estratégicas, que levam em conta diferentes públicos - ou audiências, conforme os denomina Saward (2009) -, como também a imprevisibilidade própria do discurso que circunda os processos de representação (Garcêz; Maia, 2016). Desse modo, observa-se que a frequência e a natureza das fontes de autoridade mudam quando são acionadas por pessoas surdas, conforme o Gráfico 2, abaixo. Algumas fontes de autoridade foram acionadas de forma semelhante ao geral, como os conhecimentos legais em 17 claims e os conhecimentos científicos em 16 deles. Entretanto, 0 amplo interesse, comparativamente, foi mencionado menos vezes. As histórias do povo surdo, ao contrário, foram mencionadas mais vezes pelos surdos do que pelos outros atores. 


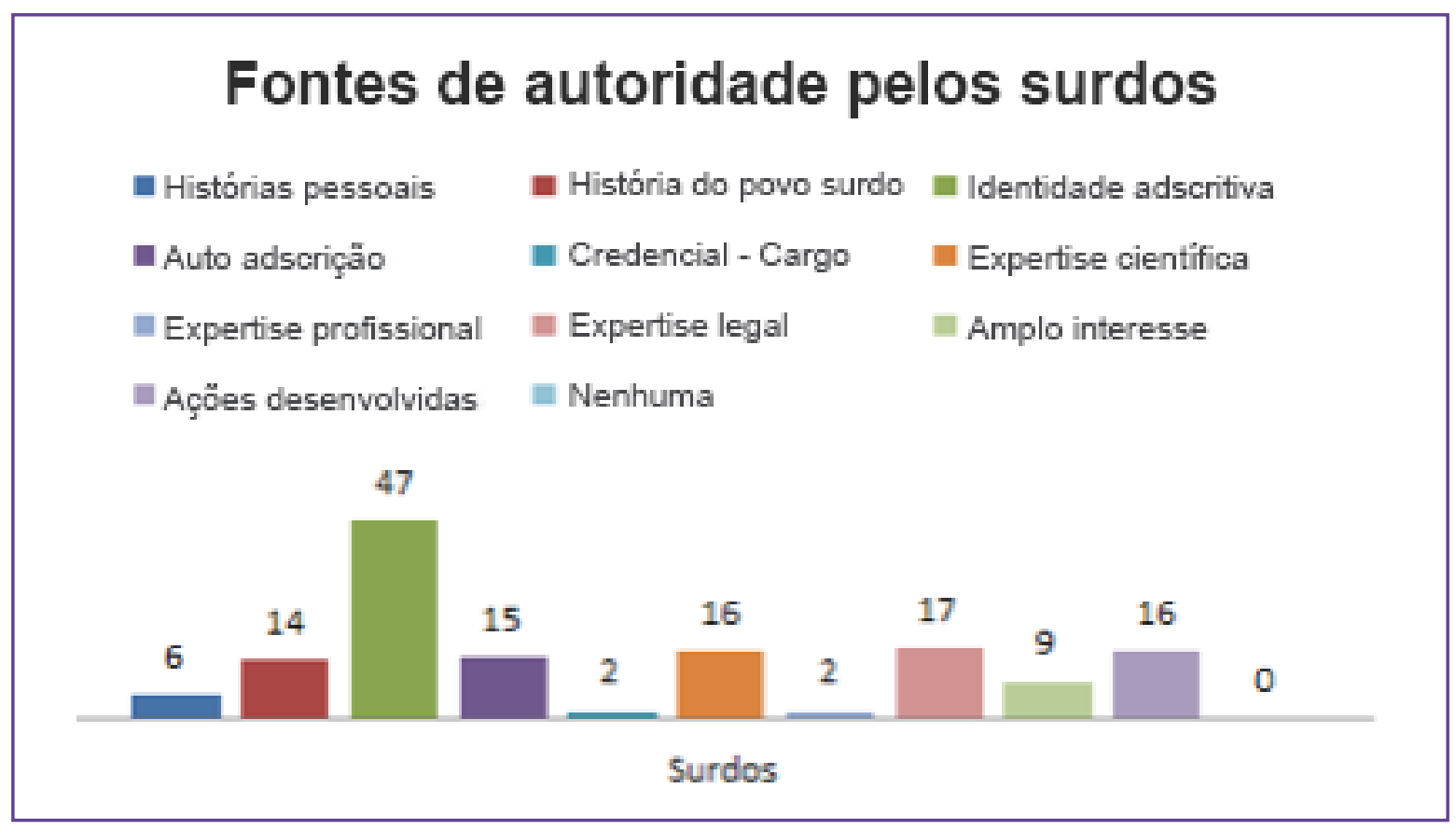

Gráfico 2: Total de fontes de autoridade acionadas pelos surdos.

As fontes de autoridade mudam também se analisarmos arena por arena, conforme o Gráfico 3:

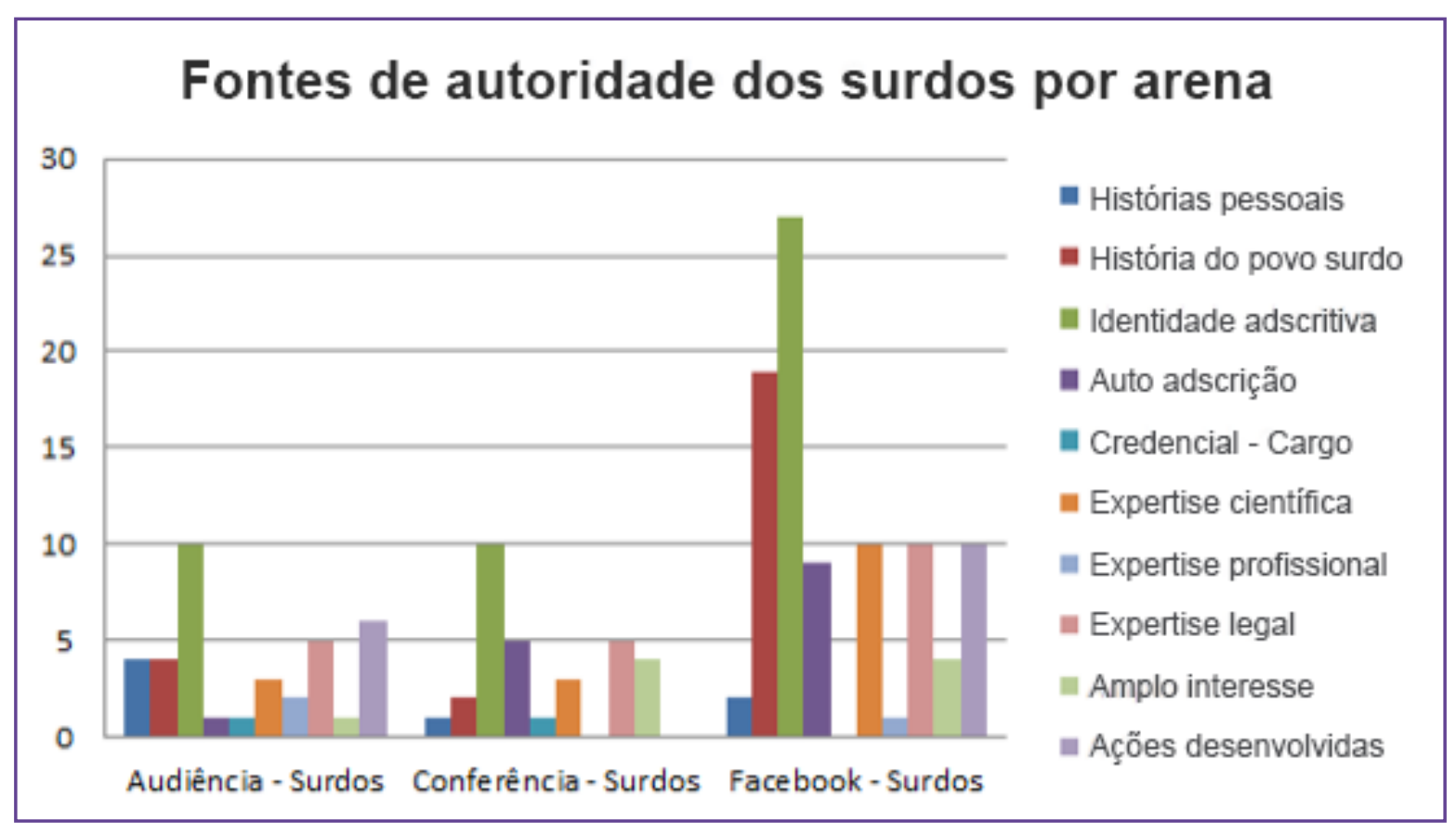

Gráfico 3: Fontes de autoridade acionadas por arena.

Conforme o gráfico acima, com exceção da identidade adscritiva, as outras fontes de autoridade são acionadas pelos surdos de formas distintas, a depender da arena, evidenciando mais uma vez essa fluidez do processo discursivo da representação. Nossa análise revela também uma diferença importante: as histórias pessoais são mais acionadas pelos não-surdos (24 vezes) do que pelos surdos (6 vezes), ao passo que a história do povo surdo é acionada 14 vezes por eles e apenas 5 por outras pessoas, com destaque para o Facebook?

Por fim, a análise aponta que as principais desconexões e distinções entre arenas são relacionadas às fontes de autoridade História do povo surdo e Amplo interesse. Entendemos que são formas distintas, fluidas e móveis de

9 Em pesquisa anterior (Garcêz; Maia, 2009), as histórias de vida dos surdos, narradas em primeira pessoa no Orkut e no site de uma organização, funcionavam como um meio de compartilhamento de vivências comuns com vistas à constituição de uma coletividade. À medida que uma história era identificada com outra se conformava uma semântica coletiva das lutas por reconhecimento dos surdos. 


\section{ANO 14 • NÚMERO 26 • 1ํㅡㄴ. 2017 - ORGANICOM REPRESENTAÇÃO POLÍTICA DISCURSIVA E MOVIMENTO SOCIAL DOS SURDOS: COLETIVIZAÇÃO DE QUESTÕES COMO FONTE DE AUTORIDADE}

coletivizar questões no ato de representar, seja por meio das histórias comuns a vários surdos do mundo ou por meio do acionamento da justificativa da ampla maioria.

No grupo do Facebook nota-se um movimento de coletivização mais intenso que nas outras arenas, mas com um ponto de partida diferente. Se antes a história de vida individual era o ponto de partida, agora a história do povo surdo se revela um meio para a constituição dessa coletividade mostrando-se uma fonte de autoridade frequentemente acionada. A proibição da língua de sinais no mundo no Congresso de Milão, em 1880, e a resistência da língua na clandestinidade fazem parte da história do movimento surdo, narrada há várias gerações. 0 valor político das histórias narradas advém da capacidade de coletivização da questão (Dryzek, 2008; Garcêz e Maia, 2009). Assim, a pertença se constitui a partir de uma construção simbólica de sentidos já coletivizados, consolidando elos que conformam essa coletividade como um exercício constante. A ideia é criar discursivamente os vínculos dessa pertença de algo que é um povo, a partir de algo que já aconteceu e que diz respeito a cada uma das lideranças e a todas elas juntas ao mesmo tempo. Por isso são acionadas predominantemente no grupo do Facebook.

Muitas vezes a história do povo surdo era associada a alguns episódios vivenciados durante a militância. Seis delegados surdos participaram em 2010 da Conferência Nacional de Educação, onde todas as propostas das escolas bilíngues foram rejeitadas. Eles se sentiram bastante discriminados na condução da votação, sendo que a moção com assinaturas necessárias sequer apareceu no documento final. Não raro essa experiência era associada ao Congresso de Milão, em que os professores surdos foram impedidos de participar das discussões e das votações sobre o uso da língua de sinais no mundo.

Vocês viram o que aconteceu na Conae? 0 mesmo que aconteceu no Congresso de Milão. Eram apenas seis surdos e mais os apoiadores ouvintes, numa plenária de quatro mil pessoas votando contra os surdos, gritando que a escola bilíngue era segregadora. (Patrícia Rezende, liderança surda - Facebook).

Experiências pessoais, ao dar ressonância a uma experiência coletiva que faz parte da ancestralidade do povo surdo (Lane; Pillard; Hedberg, 2011) - como é o caso do Congresso de Milão - conferem à representação não apenas a autoridade da pertença, mas da vivência. A demanda de representação aciona no discurso sentidos de legitimidade via experiência e pertença a uma historicidade dessa coletividade que também é apresentada nas outras arenas.

Vivenciamos uma exclusão profunda. Nós tínhamos antes as proibições do Congresso de Milão em 1880, a proibição inclusive do uso da língua de sinais, e por cem anos a língua de sinais foi subalternizada, e o resultado da educação dos surdos qual foi? Da falta do desenvolvimento das pessoas surdas, e agora, com reconhecimento da lei da Libras, nós temos que lembrar o artigo 24 da convenção que nós somos minoria linguística, e que nós temos o direito, sim, de ter uma educação na nossa língua. (Caca, liderança surda - Conferência).

O INES é histórico pra gente, tem 154 anos de existência, éa base de toda a educação, de toda a atenção às pessoas surdas deste país, um dos promotores e divulgadores da língua de sinais, e um dos marcos da cultura surda dentro da identidade surda, e passa isso pras crianças surdas que são atendidas ali ano a ano, isso de muitos anos já. (Valdo Ribeiro, surdo e representante do INES - Audiência PFDC).

Compreendemos que a coletivização das questões se dá por meio da história do povo surdo e da defesa da existência desse povo e do seu modo próprio de ver o mundo. Essa fonte de autoridade, presente nas três arenas, ganhou destaque no grupo do Facebook, no sentido de criar os nós dessa coletividade e conformar aquele grupo virtual como grupo de fato, para além da rede social, com metas de militância bem definidas. 
Já a categoria Amplo interesse acionada como fonte de autoridade revela também a coletivização de interesses, mas desta vez o coletivo é considerado de formas diferentes. 0 nós são todos os brasileiros ou toda a população. Foram identificadas demandas de representação que a) expressavam um amplo apoio popular, conduzido pela regra da maioria, b) convocavam princípios abstratos e valores universais como o direito à educação de qualidade, de liberdade de escolha e de inclusão, e c) generalizavam ou coletivizavam questões para uma maioria de pessoas surdas ou não.

Encontramos expressões do tipo "todas as pessoas têm direito à educação", "defendemos a aprendizagem e participação sem nenhum tipo de discriminação, segregação com base na deficiência física, ou sensorial, ou intelectual", "lutamos por uma educação para todos". Havia uma grande defesa pela "inclusão plena", tida como sinônimo da inclusão escolar. De forma geral, o amplo interesse era acionado mais vezes por pessoas não surdas nas três arenas.

Identificamos que a inclusão, tida como princípio abstrato, é de interesse de todos, surdos e ouvintes, defensores da escola bilíngue, especial ou inclusiva. Ao serem todos a favor da inclusão, coletivizavam valores universais mencionados acima como importantes para todos. 0 que estava em jogo era o modo como a inclusão deveria ser promovida. Os surdos rejeitavam o rótulo de segregacionistas e defendiam a inclusão.

A nossa proposta da escola bilíngue não fala de segregação. Não significa segregação. Elas são também escolas inclusivas, porque nessas escolas as outras crianças ouvintes podem estudar, desde que a língua de instrução seja a língua de sinais. Elas podem, sim, estudar com as crianças surdas. (José Carlos, delegado surdo - Conferência).

Existe um discurso de que a escola bilíngue é excludente. A escola bilíngue pode receber surdos, pessoas surdas com outras deficiências, pessoas ouvintes que queiram ser educadas na língua de sinais. Se o meu filho for ouvinte, inclusive, eu tenho a escolha de colocá-lo numa escola bilíngue, porque ele também vai saber a língua de sinais, ou em outra escola, eu quero ter o direito de escolher. As pessoas falam que nós surdos queremos segregação. Isso não é verdade. O surdo quer direito à educação em língua de sinais. No modelo atual, inclusive, as aulas não são nem em língua de sinais. São em português, e os surdos sempre vão ficar no nível abaixo das outras pessoas porque não foram escolarizados corretamente. (Mariana Hora, delegada surda - Conferência).

A inclusão é compreendida como princípio abstrato desejado por todos. A escola bilíngue não seria segregadora, mas promoveria inclusão visto que promoveria educação de qualidade. Aqui, outro princípio abstrato é acionado. A qualidade da educação é frequentemente convocada como de interesse amplo e inquestionável. Princípios e valores, ao serem traduzidos em medidas práticas por meio de políticas educacionais, ganham conotações distintas. Para os surdos, não se trata de ser contra a inclusão, mas contra o modelo de inclusão atual, chamado pelo presidente do Conade, Moisés Bauer, na audiência da PFDC, de inclusão samambaia, ou meramente decorativa.

0 amplo interesse é acionado nos discursos que defendem a liberdade de escolha, como no proferimento do surdo José Carlos na Conferência: "As pessoas são livres, têm o direito de escolher o melhor caminho para suas vidas! Onde é que está, aqui, a liberdade e a igualdade?" Ou, ainda, na fala da liderança surda Patrícia Rezende: "Nós temos esse direito de escolha de como gostaríamos de ser escolarizados".

Por fim, o amplo interesse foi identificado em discursos de generalização e apagamento das diferenças, particularmente por parte dos gestores do MEC. Com o argumento de que a educação é para todos, muitas vezes as especificidades das deficiências eram desconsideradas. Na conferência, isso foi identificado por meio de tentativas de suprimir dos textos a expressão educação de surdo e outras particularidades das deficiências, substituindo-as pelo termo público alvo da educação especial. A justificativa era de que a educação tem que ser para todos. Ainda que fossem políticas para as pessoas com deficiência, elas eram mencionadas no sentido de apagarem as diferenças internas ao grupo. 


\section{CONSIDERAÇÕES FINAIS}

O estudo buscou mostrar como a noção de representação política não eleitoral pode auxiliar na compreensão da comunicação estratégica exercida pelos movimentos sociais, considerando sua característica móvel e discursiva. Buscouse evidenciar os meios pelos quais representantes e porta-vozes procuram alcançar legitimidade por meio das fontes de autoridade, acionadas de formas diferentes, a depender da audiência/público, tanto em função das estratégias adotadas quanto da imprevisibilidade própria dos discursos de representação. Concluímos que a coletivização de interesses, seja em um grupo identitário ou em toda a sociedade, é uma importante fonte de autoridade. Por outro lado, destaca-se que essa coletivização apresenta nuances distintas, estabelecendo diferentes nós ou coletividades, conforme observamos tanto no acionamento de histórias do povo surdo, que considerava como coletividade os surdos, quanto na defesa do amplo interesse, na qual o coletivo era composto pelo todo da sociedade.

\section{REFERÊNCIAS}

AVRITZER, Leonardo. Sociedade civil, instituições participativas e representação: da autorização à legitimidade da ação. Dados [online], v. 50, n. 3, p. 443-464, 2008.

CAMPELLO, Ana Regina S.; REZENDE, Patrícia L. Em defesa da escola bilíngue para surdos: a história de lutas do movimento surdo brasileiro. Educar em Revista, Curitiba, Editora da UFPR, edição especial n. 2, p. 71-92, 2014.

DRYZEK, John S.; NIEMEYER, Simon. Discursive representation. American Political Science Review, p. 481-493, 2008.

FARIA-NASCIMENTO, Sandra Patrícia; COSTA, Messias Ramos. Movimentos surdos e os fundamentos e metas da escola bilíngue de surdos: contribuições ao debate institucional. Educar em Revista, v. 1, p. 159-18, 2014.

GARCÊZ, Regiane L. de Oliveira. A representação política dos oprimidos nas redes sociais online: Quem fala em nome de quem e com qual legitimidade?. Contemporânea(Online), UFBA, v. 11, p. 304-321, 2013.

GARCÊZ, Regiane L. de Oliveira; MAIA, Rousiley C.M. Representação política não-eleitoral na perspectiva processual: discursividade e estratégia no debate sobre a educação de surdos. Compolítica, v. 6, p. 7-34, 2016.

GUTMANN, Amy. Identity in democracy. Princeton, NJ: Princeton University Press, 2003.

LANNA JÚNIOR, Mário Cléber Martins (Comp.). História do Movimento Político das Pessoas com Deficiência no Brasil. Brasília: Secretaria de Direitos Humanos - Secretaria Nacional de Promoção dos Direitos da Pessoa com Deficiência, 2010.

LANE , Harlan; PILLARD , Richard C.; HEDBERG , Ulf. The people of the eye: deaf ethnicity and ancestry. New York: Oxford University Press, 2011.

MAIA, Rousiley C. M. Non-electoral political representation: expanding discursive domains. Journal Representation, v. 48, p. 429-443, 2012.

MANSBRIDGE, Jane. Rethinking representation. American Political Science Review, n. 97, p. 515-528, 2003. 
MANSBRIDGE, Jane et al. A systemic approach to deliberative democracy. In: PARKINSON, John; MANSBRIDGE, Jane J. Deliberative systems: deliberative democracy at the large scale. New York: Cambridge University Press, 2012. p.1-26.

McCARTHY, John D.; ZALD, Mayer N. Social movement organizations. In: GOODWIN, Jeff; JASPER, James M. (Eds.). The social movements reader. cases and concepts. 2nd ed. Wiley-Blackwell Malden: Massachusetts [Reader]. 2009. p. 193-210.

MELUCCI, Alberto. Challenging codes: collective action in the information age. Cambridge: Cambridge University Press, 1996.

PITKIN, Hanna F. The concept of representation. Berkeley, CA: University of California Press, 1967.

SAWARD, Michael. Authorization and authenticity: representation and the unelected. The Journal of Political Philosophy, v. 17, n. 1, p. 1-22, 2009.

The representative claim. Nova York: Oxford University Press, 2010.

SNOW, David A. Framing processes, ideology, and discursive fields. In: SNOW, David A.; SOULE, Sarah A.; KRIESI, Hanspeter. The Blackwell companion to social movement. Oxford: Blackwell Publishing, 2004. p. 380-412.

TARROW, Sidney G. Power in movement. social movements and contentious politics. Cambridge, UK: Cambridge University Press, 1998.

TILLY, Charles. The politics of collective violence. Cambridge, UK: Cambridge University Press, 2003.

URBINATI, Nadia. Representative democracy. Chicago, IL: The University of Chicago Press, 2006.

URBINATI, Nadia; WARREN, Mark E. The concept representation in contemporary democratic theory. The Annual Review Political Science, v. 11, p. 387-412, 2008.

YOUNG, Iris Marion. Inclusion and democracy. Oxford: Oxford University Press, 2000.

WARREN, Mark E. Democracy and association. Princeton: Princeton University Press, 2001.

WELDON, S. Laurel. When protest makes policy. how social movements represent disadvantaged groups. Ann Arbor, Ml: University of Michigan Press, 2011.

Texto recebido em 10.04.2017 e aprovado em 30.06.2017. 